\title{
ECOLOGICAL CORRELATES OF MORPHOLOGICAL EVOLUTION IN A DARWIN'S FINCH, GEOSPIZA DIFFICILIS
}

\author{
Dolph Schluter ${ }^{1}$ and Peter R. Grant \\ Division of Biological Sciences, The University of Michigan, Ann Arbor, Michigan 48109
}

Received July 15, 1982. Revised December 20, 1983

Morphological variation among different island populations is a familiar attribute of many species of Darwin's finches. Lack (1947) provided the first detailed arguments for the adaptive significance of morphological variation in this group. He stressed two aspects: first, that several morphological features are related to feeding, and second, that morphological differences between populations may be associated with inter-island differences in the type and number of potentially competing species.

A specific example is the sharp-beaked ground finch, Geospiza difficilis. This species is widely distributed in the Galápagos archipelago and occurs with a variety of combinations of congeneric species (Fig. 1). Lack argued that the population on Genovesa resembles the absent species $G$. fuliginosa. Two other populations on the low islands of Darwin and Wolf resemble the cactus finch, $G$. scandens, where both this species and $G$. fuliginosa are absent (Lack, 1947). Geospiza difficilis populations on the more central highland islands are intermediate between these two extremes. From these data Lack inferred that on Genovesa $G$. difficilis occupies the feeding niche exploited by $G$. fuliginosa on other islands, and that on Darwin and Wolf it combines the niches of $G$. fuliginosa and $G$. scandens (Fig. 1). Lack considered this as evidence in support of his general thesis that competition had influenced the adaptive radiation of the finches.

Lack based these conclusions largely

\footnotetext{
1 Present address: Department of Zoology, University of British Columbia, Vancouver, British Columbia, Canada V6T 2A9.
}

upon morphological study of museum specimens. Hence a central assumption of his arguments is that morphological differences between $G$. difficilis, $G$. fuliginosa and $G$. scandens adequately reflect differences in diet. In this report we use morphological and ecological data from $G$. difficilis populations to investigate this central assumption. Geospiza difficilis is particularly useful for this type of study because it is morphologically one of the most differentiated species of Darwin's finches (Lack, 1947; Grant, 1981; Grant and Schluter, 1984). Our purposes are threefold:

1. To characterize, more quantitatively than Lack did, interpopulation variation in the morphology of $G$. difficilis and the morphology of this species in relation to the two most similar congeners, $G$. fuliginosa and $G$. scandens.

2. To compare diets of different $G$. difficilis populations with their morphologies, and with the diets of the two morphologically similar species, $G$. fuliginosa and $G$. scandens.

3. To combine information on feeding and morphology with data on food supply in order to interpret trends of morphological evolution in $G$. difficilis.

Lack's method of inferring feeding niches from morphological data is commonly used, especially to examine patterns in the assembly and evolution of ecological communities (e.g., Keast, 1972; Gatz, 1979; Ricklefs and Travis, 1980; Ricklefs et al., 1981; Simberloff and Boecklen, 1981 and references therein; Grant and Schluter, 1984). Since the validity of such inference has rarely been 


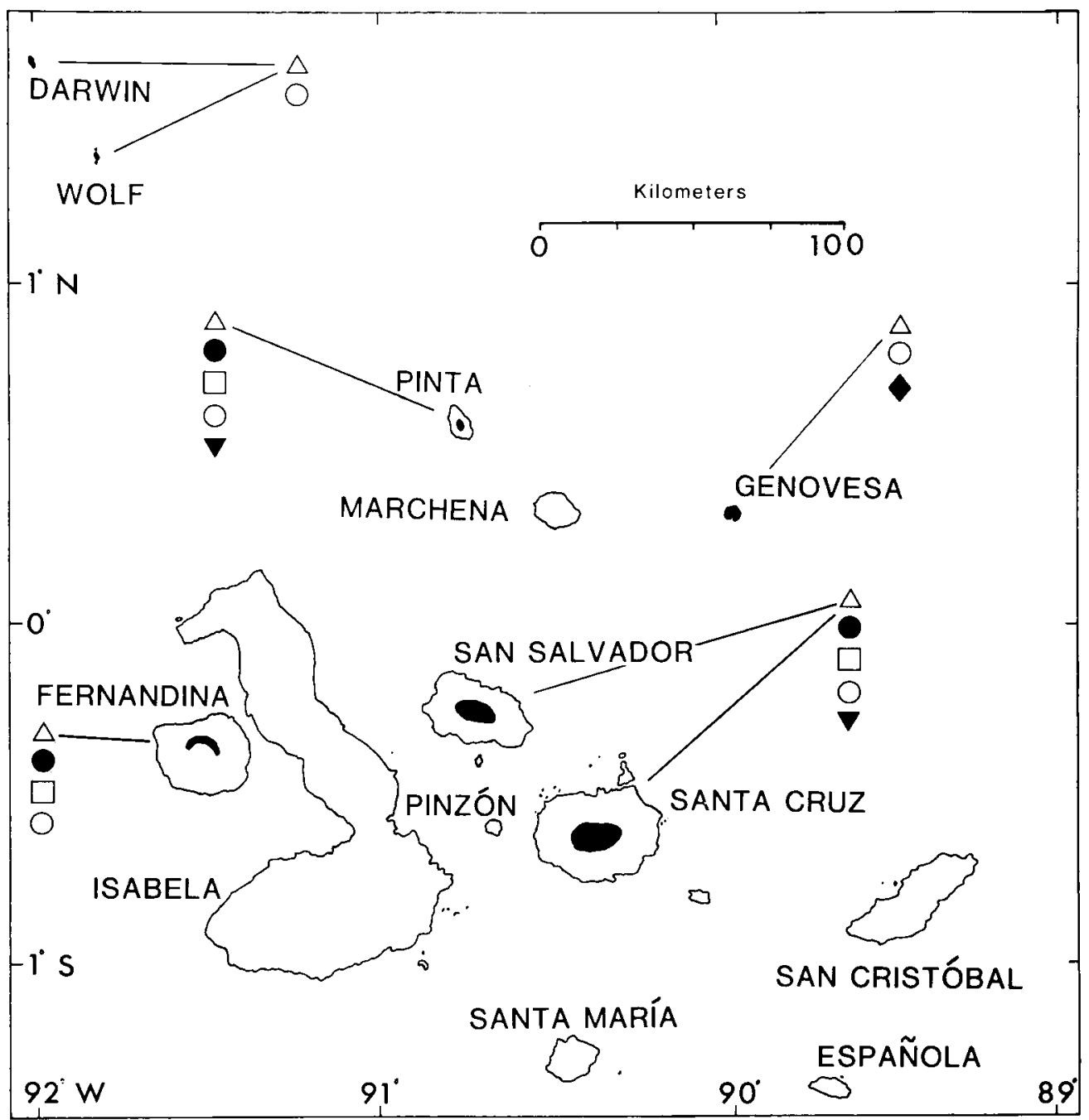

FIG. 1. The distribution of $G$. difficilis ( $\triangle$; darkened regions) in relation to congeneric species (after Lack, 1947). Lack (and Harris, 1973) were uncertain as to the presence of $G$. difficilis on Fernandina: it has a large population there (this study). Lack also mentioned the possibility of a $G$. difficilis population on southern Isabela. Habitat destruction may have caused its extinction there, as apparently happened on Santa Maria (Lack, 1947). The species is now extinct on Santa Cruz. Congeners are the small ( $G$. fuliginosa; $)$, medium $(G$. fortis; $\square$ ) and large ( $G$. magnirostris; $O)$ ground finches, and the cactus finches, $G$. scandens $(\boldsymbol{\nabla})$ and $G$. conirostris $(\vec{\nabla})$. As Lack noted, $G$. difficilis is found mainly in the highlands except on the low islands of Darwin, Wolf and Genovesa, where G. fuliginosa is absent.

examined (James, 1982), the present analysis may be of general significance.

\section{Methods}

Nine islands were visited during the study (Table 1), and measurements were taken on morphology, density, diets and food supplies of finches.

\section{Study Sites}

The islands visited include all six islands on which $G$. difficilis is presently 
TABLE 1. Dates of visits to islands, and sample sizes for finch measurements. Values in parentheses refer to birds in partly or fully black plumage (adult males). Measurements, made by both authors and D. J. Anderson (DA), were not all made on the dates shown. Maximum elevations are from Wiggins and Porter (1971).

\begin{tabular}{|c|c|c|c|c|c|c|}
\hline \multirow[b]{2}{*}{ Island } & \multirow{2}{*}{$\begin{array}{c}\text { Maximum } \\
\text { elevation }\end{array}$} & \multirow[b]{2}{*}{ Dry-season dates } & \multicolumn{3}{|c|}{ No. specimens measured } & \multirow{2}{*}{$\begin{array}{c}\text { Person } \\
\text { measuring }\end{array}$} \\
\hline & & & difficilis & fuliginosa & scandens & \\
\hline \multicolumn{7}{|l|}{ High } \\
\hline Pinta & $777 \mathrm{~m}$ & 28 Oct-3 Dec 1979 & $35(22)$ & $149(72)$ & $29(19)$ & DS \\
\hline San Salvador & $905 \mathrm{~m}$ & 13 Sept-8 Oct 1981 & $25(13)$ & $56(28)$ & - & DS \\
\hline Fernandina & $1,494 \mathrm{~m}$ & 9 Oct-5 Nov 1981 & $16(11)$ & $26(15)$ & - & DS \\
\hline \multicolumn{7}{|l|}{ Low } \\
\hline Darwin & $168 \mathrm{~m}$ & 12 Sept 1981 & $22(4)$ & - & - & DS \\
\hline Wolf & $253 \mathrm{~m}$ & 10-11 Sept 1981 & $45(21)$ & - & - & $P G$ \\
\hline Genovesa & $76 \mathrm{~m}$ & 17 Sept-13 Oct 1979 & $92(49)$ & - & - & PG \\
\hline Marchena & $343 \mathrm{~m}$ & 4-27 Oct 1979 & - & $18(11)$ & $4(2)$ & DS \\
\hline Española & $198 \mathrm{~m}$ & 11-26 Nov 1981 & - & $23(12)$ & - & DA \\
\hline Tortuga & $186 \mathrm{~m}$ & 7-10 Nov 1981 & - & $25(8)$ & - & DA \\
\hline
\end{tabular}

found (Fig. 1). Three additional islands, Marchena, Española and Tortuga, were added to the list in order to increase the sample size of $G$. fuliginosa measurements and observations. At least one, and up to six, 1-ha study sites were established on each island depending upon time constraints and the diversity of habitats. On high elevation islands (Table 1), sites were altitudinally spaced so as to represent each of the three major vegetation zones: arid, transition, and humid forest (Wiggins and Porter, 1971). The approximate locations of sites are: Pinta, 6 sites spaced ca. $.5 \mathrm{~km}$ apart along $S$ trail to summit, from $110 \mathrm{~m}$ elevation to 510 $\mathrm{m}$; San Salvador, sites at Caleta Bucanero (coast), at $670 \mathrm{~m}$ elevation near trail on $\mathrm{N}$ slope, and at $830 \mathrm{~m}$ on $\mathrm{S}$ slope immediately below main summit; Fernandina, 3 adjacent sites along NW crater edge at summit above Cabo Douglas $(1,300 \mathrm{~m})$, and one site along coast $3 \mathrm{~km}$ NE C. Douglas; Darwin, 1 site on landslide area above landing on NW side; Wolf, 1 site at the eastern half of NW plateau; Genovesa, 3 sites at Bahía Darwin, in the same location as the one used by Abbott et al. (1977); Marchena, 1 site behind $\mathrm{E}$ point of Playa Grande, and a second on hilltop above lava plains $3 \mathrm{~km}$ uphill and NE (170 m); Española, 1 site behind Bahía Gardner in the same location as the one used by Abbott et al. (1977), and 2 others $1 \mathrm{~km}$ and $2 \mathrm{~km}$ directly inland (30 and $85 \mathrm{~m}$ ); Tortuga, 1 site $\mathrm{N}$ slope immediately below ridge $(130$ m). Site descriptions for Pinta, Marchena, and Genovesa are given in Schluter $(1982 a)$ and Schluter and Grant (1982).

Climate in the Galápagos is highly seasonal, with a hot/wet season (ca. January-May) and a cool/dry season (JuneDecember) (Grant and Boag, 1980). All islands were visited in a dry season (Table 1), though several were visited also during a wet season. Effort was concentrated in the dry season because at that time standing crop and production of foods reach their lowest values. There is evidence that finch populations become food-limited then, and at this time diet should reflect morphology most closely (Smith et al., 1978; Boag and Grant, 1981; Schluter, 1982a). Finches usually breed only in the wet season.

Goats have been introduced onto the islands of Pinta, San Salvador and Española. Extermination programs have eliminated their populations on Pinta (almost) and Española (completely). Vege- 
TABLE 2. Untransformed measurement means and standard deviations (in parentheses) for adult male $G$. difficilis. Measurements for male $G$. fuliginosa and $G$. scandens, averaged over populations, are provided for comparison. Mass is in $\mathrm{g}$, the remainder are in $\mathrm{mm}$. Sample sizes are in Table 1.

\begin{tabular}{|c|c|c|c|c|c|c|c|}
\hline & Body mass & Wing length & $\begin{array}{l}\text { Tarsus } \\
\text { length }\end{array}$ & Beak length & $\begin{array}{l}\text { Beak } \\
\text { depth }\end{array}$ & $\begin{array}{c}\text { Beak } \\
\text { width }\end{array}$ & $\begin{array}{c}\text { Beak } \\
\text { length } \\
\text { at } 4 \mathrm{~mm}\end{array}$ \\
\hline \multicolumn{8}{|l|}{ difficilis } \\
\hline Pinta & $19.0(1.1)$ & $63.1(1.4)$ & $19.4(.57)$ & $9.8(.25)$ & $7.2(.19)$ & $7.1(.16)$ & $4.6(.14)$ \\
\hline San Salvador & $26.8(2.3)$ & $71.2(1.9)$ & $21.6(.68)$ & $10.2(.49)$ & $7.6(.21)$ & $8.0(.17)$ & $4.1(.23)$ \\
\hline Fernandina & $19.6(1.1)$ & $65.6(1.7)$ & $20.7(.56)$ & $9.3(.40)$ & $6.9(.22)$ & $7.0(.23)$ & $4.5(.30)$ \\
\hline Darwin & $25.5(2.5)$ & $74.0(1.4)$ & $22.7(.62)$ & $11.5(.45)$ & $7.9(.24)$ & $7.8(.43)$ & $4.4(.21)$ \\
\hline Wolf & $20.5(.79)$ & $74.6(2.3)$ & $20.8(.40)$ & $11.1(.35)$ & $7.1(.23)$ & $7.2(.28)$ & $4.9(.26)$ \\
\hline Genovesa & $11.6(.66)$ & $64.0(1.8)$ & $18.1(.47)$ & $9.6(.44)$ & $6.4(.27)$ & $6.5(.28)$ & $5.1(.28)$ \\
\hline fuliginosa & 13.3 & 62.1 & 17.9 & 8.6 & 6.9 & 6.8 & 3.8 \\
\hline scandens & 21.8 & 73.1 & 21.1 & 14.5 & 9.1 & 8.7 & 4.8 \\
\hline
\end{tabular}

tation and soil have recovered signifcantly on Pinta, but not on Española where they are still visibly affected, and not on San Salvador where goats have been present since 1813 (Hamann 1979, 1981; pers. observ.). Pigs, donkeys and rats have also been introduced to San Salvador. Undoubtedly the disturbance has affected finch feeding patterns to some extent, especially on the latter islands.

\section{Finch Diets and Food Supply}

Study procedures are described in Schluter (1982 $a$ and references therein). Briefly, an observer walked along a predetermined route and recorded the amount of time that individual finches spent feeding on specific food types. These finches are tame and may be approached closely, and food items could usually be identified directly in the beak, or indirectly from the parent plant. A maximum of 300 observations per bird was set so that information could be obtained from as many birds as possible. All data were collected by two observers, with consistent results.

Food supply was assessed on all islands in the dry season, excepting Darwin where time did not permit this. Twenty-five (occasionally 50 ) random $1 \mathrm{~m}^{2}$ quadrats were located in each site. In each quadrat, the percent cover of plant species, the abundance of seeds and fruits on the vegetation, and the number of flowers were determined. In addition seeds on rock surfaces in two subquadrats of .125 $\mathrm{m}^{2}$ were counted. All litter and surface soil (to a depth of $2.5 \mathrm{~cm}$ ) within these subquadrats was collected in bags and subsequently examined for seeds and invertebrates. Dry mass of both these food types was later assessed in the laboratory.

\section{Finch Morphology}

Seven characters were measured on live finches captured in nets. Characters represent different aspects of body or beak size, and hence they are among the traits most likely to be related to feeding. Body Mass was determined to the nearest $.1 \mathrm{~g}$ with a spring balance. The remaining characters were measured to the nearest $.1 \mathrm{~mm}$ : Wing Length, from the metacarpal bend to the tip of the longest primary, with the wing held flat against a rule; Tarsus Length, with dividers, from the tibiotarsal joint to the distal end of the first scute surrounding the tarsus that was wider than its length; Beak Length, measured with dividers, from the anterior end of the nares to the tip of the upper mandible. The remaining three traits were measured using vernier calipers: Beak Depth, measured at the anterior end of the nares perpendicular to the commissure; Beak Width, the width of the lower mandible at the widest part, near the base; and Beak Length at $4 \mathrm{~mm}$, the distance from the point along the commissure at 
TaBle 3. Factor loadings for the first three principal components derived from mean morphology in populations of $G$. difficilis (adult males). Values in parentheses give the fraction of the variation accounted for in each trait (Pimentel, 1979). Also given is the cumulative total variance accounted for by the addition of successive components. $N=6$ populations.

\begin{tabular}{lccc}
\hline \hline \multirow{2}{*}{\multicolumn{1}{c}{ Variables }} & \multicolumn{3}{c}{ Scores and variance fractions } \\
\cline { 2 - 4 } & \multicolumn{1}{c}{ PC1 } & PC2 & PC3 \\
\hline Wing length & $.37(.67)$ & $.42(.24)$ & $-.56(.07)$ \\
Tarsus length & $.47(.92)$ & $-.04(.00)$ & $-.44(.04)$ \\
Beak length & $.38(.57)$ & $.60(.40)$ & $.41(.03)$ \\
Beak depth & $.41(.91)$ & $-.11(.02)$ & $.55(.07)$ \\
Beak width & $.45(.92)$ & $-.21(.06)$ & $.12(.00)$ \\
Beak length at 4 mm & $-.36(.53)$ & $.63(.47)$ & $.08(.00)$ \\
\hline \% variance & 74.7 & 95.3 & 98.8 \\
\hline
\end{tabular}

which the depth of the beak is $4 \mathrm{~mm}$, to the tip of the upper mandible. Unlike previous 'size' variables, Beak Length at $4 \mathrm{~mm}$ is essentially a 'shape' variable, measuring beak pointedness at the tip. Its magnitude within species is dependent upon Beak Length and Beak Depth, but differences between species, especially $G$. fuliginosa and $G$. difficilis, are due mainly to differences in beak curvature independent of differences in Beak Length and Depth.

Sample sizes are given in Table 1, and descriptive statistics are provided in Table 2. Measurements from different populations were made by three persons and at different periods over 1978 to 1981 . Identical methods were used throughout. Boag (1983) has shown high repeatabilities (Falconer, 1981) for these traits in $G$. fortis and $G$. scandens individuals measured at different times and by different persons.

Measurements of adult male $G$. scandens from Santa $\mathrm{Fe}(N=5)$, Champion $(N=6)$ and Daphne $(N=105)$ by P.R.G. and $P$. T. Boag were included in the comparative analyses to improve the sample size for this species.

\section{RESULTS}

We begin with a brief description of the general morphology of $G$. difficilis, and compare it to the morphologies of $G$. fuliginosa and $G$. scandens. Diets are then described in relation to food avail- ability, and diet differences between populations are compared with differences in morphology.

\section{Multivariate Patterns}

Principal components analysis on $\log (10)$-transformed measurements (PCA; Pimentel, 1979) was used to represent multivariate differences among populations of $G$. difficilis, and similarities with other species. Two separate PCA's were performed. In the first, components were extracted from a six-variable covariance matrix computed from all $G$. difficilis individuals combined. The second PCA used the covariances computed from the population means for adult males only. Means for males differ significantly among populations (ANOVA, $P<.001$ ), and are larger than female means (Price, 1984). Body Mass was not included in either analysis because it is given in different units from the other variables. The two analyses gave almost identical results, and we use only the second.

The first component (PC1) explains a large amount of the variance in all of the original 'size' variables, and accounts for a large amount of the total variation among $G$. difficilis populations (Table 3 ). Body Mass, highly variable among these populations (Table 2) is also highly correlated with PC1 $(r=.95)$. PC1 may thus be considered a general body size variable (Pimentel, 1979). 


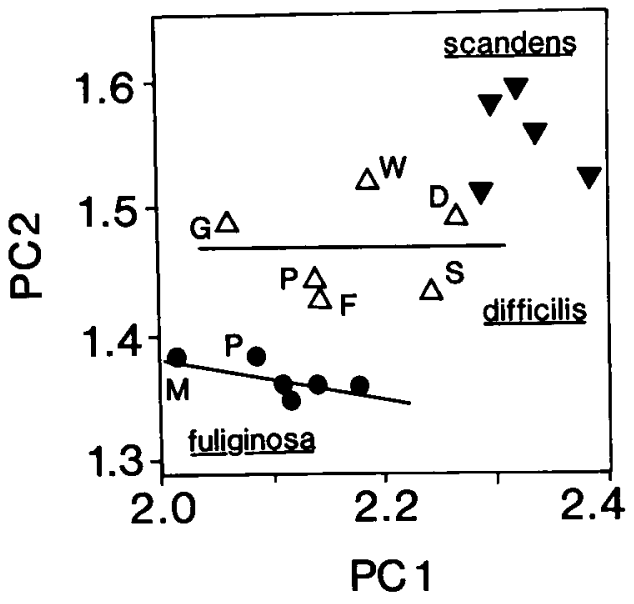

FIG. 2. Population means for adult male $G$. difficilis, $G$. fuliginosa, and $G$. scandens along the first two morphological principal components. Loadings for original variables are given in Table 3. Components are derived from population means for adult male $G$. difficilis only. Solid line through $G$. fuliginosa points is the first principal axis derived from population means $(N=6)$ projected onto the $\mathrm{PC} 1-\mathrm{PC} 2$ plane through the overall $G$. fuliginosa mean. The axis accounts for $89 \%$ of the variance among $G$. fuliginosa means. $\mathrm{PC} 1$ was redrawn through the overall $G$. difficilis mean for comparison. Island symbols for $G$. difficilis are Pinta $(\mathrm{P})$, San Salvador (S), Fernandina (F), Darwin (D), Wolf (W), and Genovesa (G). Geospiza fuliginosa forms are unlabelled except for those on Pinta (P) and Marchena (M).

PC2 is essentially a function of only three traits, Wing Length, Beak Length, and Beak Length at $4 \mathrm{~mm}$, and hence may be said to incorporate population differences in shape. Together PC1 and PC2 account for over $95 \%$ of total variation among populations; PC3 and subsequent components contribute substantially less $(\leq 3.5 \%)$.

Figure 2 shows the positions of means for individual populations along $\mathrm{PC} 1$ and $P C 2$. In size (PC1) the Genovesa population is the smallest form, and San Salvador and Darwin are the largest. Populations on Darwin and Wolf possess the relatively longest wings, and the longest, most pointed beaks (PC2). In the three highland forms the wing is relatively short, and the beak relatively short and blunt.
TABLE 4. Morphological distance $(M)$ and diet difference $(D)$ between each $G$. difficilis population and the unweighted mean of $G$. fuliginosa and $G$. scandens populations. $M$ is the Euclidean distance based on the six morphological variables from which principal components were derived (Table 3 ). $D$ is $1 / 2$ the Manhattan distance, and varies from 0 (no difference) to 1 (maximum difference). $1-\mathrm{D}$ is the familiar Renkonen index of niche overlap (Hurlbert, 1978). Data are from Table 5. Underlined values indicate islands where $G$. fuliginosa and $G$. scandens are absent, but their major foods are present. Geospiza scandens is absent from Genovesa but is replaced there by $G$. conirostris (Fig. 1). Fernandina also lacks $G$. scandens, but cactus is uncommon there (pers. observ.).

\begin{tabular}{llllll}
\hline \multirow{2}{*}{\multicolumn{1}{c}{ difficilis }} & \multicolumn{2}{c}{ fuliginosa } & & \multicolumn{2}{c}{ scandens } \\
\cline { 2 - 3 } \cline { 5 - 6 } \cline { 5 - 6 } Pinta & $\mathrm{M}$ & $\mathrm{D}$ & & $\mathrm{M}$ & $\mathrm{D}$ \\
Fernandina & .11 & .77 & & .23 & .97 \\
Genovesa & .10 & .74 & & .25 & .95 \\
San Salvador & $\underline{.14}$ & .33 & & .28 & .91 \\
Wolf & .15 & .69 & & .19 & .95 \\
Darwin & $\underline{.19}$ & .56 & & .18 & .88 \\
\hline
\end{tabular}

Mean scores for adult males were also determined on the same axes for populations of $G$. fuliginosa and $G$. scandens (Fig. 2) to allow a direct comparison with $G$. difficilis. These two axes account for $80.4 \%$ of the variance among population means for all three species combined. The relationships among populations and species shown are the same when the PC's are instead determined from the combined species pool. Geospiza scandens is larger than $G$. difficilis and has a relatively long and pointed beak, and relatively long wings. Geospiza fuliginosa is slightly smaller, with a relatively short, blunt beak.

The data in Figure 2 are largely consistent with Lack's (1947) original comparison. The Genovesa form of $G$. difficilis is similar to $G$. fuliginosa in size, notably Tarsus Length and also Body Mass (Table 2). The Darwin and Wolf populations are similar to $G$. scandens in both size and shape. However, the morphological relations among populations and species are more complex than Lack realized. For example, populations of $G$. 
TABLE 5. Dry-season proportions of time spent feeding on foods of different types and in different feeding positions. Dates are given in Table 1 . Values are averages over all sites, weighted by the density of birds (census walk estimates). Daphne data are from Sept. 1979, provided by S. J. Millington. Geospiza scandens diets are not available for other sites. See text for description of diet categories. Values $\geq 10 \%$ of diet are given in boldface.

\begin{tabular}{|c|c|c|c|c|c|c|c|c|c|c|c|}
\hline & \multicolumn{3}{|c|}{ Ground } & \multicolumn{2}{|c|}{ Vegetation } & \multirow[b]{2}{*}{$\begin{array}{l}\text { Pollen } \\
\text { nectar }\end{array}$} & \multirow[b]{2}{*}{$\begin{array}{c}\text { Opun- } \\
\text { tia }\end{array}$} & \multirow[b]{2}{*}{$\begin{array}{c}\text { Scav- } \\
\text { eng- } \\
\text { ing }\end{array}$} & \multirow[b]{2}{*}{ Blood } & \multirow[b]{2}{*}{ Other } & \multirow[b]{2}{*}{$\begin{array}{l}\text { No. sec. } \\
\text { obs. }\end{array}$} \\
\hline & $\begin{array}{c}\text { In- } \\
\text { verte- } \\
\text { brates }\end{array}$ & $\begin{array}{l}\text { Con- } \\
\text { cealed } \\
\text { seeds }\end{array}$ & $\begin{array}{c}\text { Ex- } \\
\text { posed } \\
\text { seeds }\end{array}$ & $\begin{array}{c}\text { In- } \\
\text { verte- } \\
\text { brates }\end{array}$ & Seeds & & & & & & \\
\hline \multicolumn{12}{|l|}{ difficilis } \\
\hline Pinta & .78 & .17 & .01 & .04 & .01 & & & & & & 38,915 \\
\hline San Salvador & .59 & .30 & .04 & .07 & & & & & & & 14,150 \\
\hline Fernandina & .02 & .93 & .05 & & & & & & & & 9,705 \\
\hline Darwin & .29 & .28 & .34 & & .06 & & & .02 & .01 & & 5,045 \\
\hline Wolf & & .60 & .17 & .04 & & & .05 & .04 & .07 & .02 & 17,535 \\
\hline Genovesa & .04 & .29 & .36 & & .02 & .23 & .02 & .05 & & & 41,990 \\
\hline \multicolumn{12}{|l|}{ fuliginosa } \\
\hline Pinta & & .05 & .16 & .05 & .63 & .10 & .01 & & & .02 & 103,990 \\
\hline San Salvador & & .24 & .54 & .01 & .19 & & & & & .02 & 26,405 \\
\hline Fernandina & & .07 & .61 & .01 & .29 & .01 & & & & & 25,870 \\
\hline Marchena & .01 & & .49 & & .21 & .28 & & & & & 51,960 \\
\hline Española & & .56 & .08 & .01 & & & & & & .34 & 25,365 \\
\hline Tortuga & & & .59 & .30 & & & & .12 & & & 10,868 \\
\hline \multicolumn{12}{|l|}{ scandens } \\
\hline Pinta & & & & & & & 1.00 & & & & 2,900 \\
\hline Daphne & & & .11 & .03 & .03 & & .84 & & & & $t$ \\
\hline
\end{tabular}

difficilis on Fernandina (not examined by Lack) and Pinta are also similar to $G$. fuliginosa in size and shape (Fig. 2). This is confirmed in Table 4, which summarizes morphological distances between species. The Fernandina, Pinta, and Genovesa forms of $G$. difficilis are all quite close to the overall mean for $G$. fuliginosa. The Darwin form of $G$. difficilis is most similar to $G$. scandens, with Wolf and San Salvador farther off and essentially equidistant. These distance relationships are the same if Body Mass (cube root) is included with the other six variables, or if the analysis is restricted to the three dimensions that Lack measured: Wing Length, Beak Length, and Beak Depth.

\section{Diets and Food Availability}

Geospiza populations are most likely to be food-limited in the dry season, and at this time diets should most closely reflect morphological attributes (Smith et al., 1978; Grant and Grant, 1980a). Dry season diets are shown in Table 5. The food spectrum is divided on the basis of both food type and foraging position; previous study has shown that both aspects of the feeding niche distinguish $G$. difficilis from $G$. fuliginosa and $G$. scandens (Schluter, 1982a). This classification obscures some differences between species within categories (e.g., food size differences) but these are small compared to differences among categories. In general $G$. fuliginosa and $G$. difficilis do not differ in the ranges of seed size consumed. However, G. scandens usually takes larger seeds than both these species (Abbott et al., 1977; pers. observ.).

Concealed seeds (Table 5) refer to those obtained by digging in the litter or by shoving aside small stones. Most ground invertebrates are obtained in the same way. Exposed seeds are removed directly from the soil, rock, or litter surface. Scavenged items include decaying fish, seabird eggs, and undigested fecal remains from seabirds. Blood is a special cate- 
TABLE 6. Factor loadings for the first four principal diet components (DC1-4) in populations of $G$. fuliginosa, $G$. difficilis, and $G$. scandens (Table 5). The cumulative variance accounted for by successive components is given below. $N=14$ populations.

\begin{tabular}{lcrrr}
\hline & \multicolumn{3}{c}{ Scores } \\
\cline { 2 - 5 } \multicolumn{1}{c}{ Variables } & DC1 & DC2 & \multicolumn{1}{c}{ DC3 } & DC4 \\
\hline Ground invertebrates & -.16 & .35 & -.82 & .07 \\
Ground concealed seeds & -.43 & .55 & .54 & -.01 \\
Ground exposed seeds & -.15 & -.62 & .08 & .50 \\
Vegetation invertebrates & -.01 & -.07 & -.05 & .19 \\
Vegetation seeds & -.03 & -.34 & -.02 & -.82 \\
Pollen and nectar & -.02 & -.13 & -.01 & -.09 \\
Opuntia & .87 & .22 & .13 & .07 \\
Scavenging & -.01 & -.03 & -.01 & .11 \\
Blood & -.01 & .00 & -.02 & .01 \\
\% Variance & 38.8 & 68.0 & 87.6 & 95.6
\end{tabular}

gory: $G$. difficilis on Wolf is known to draw and consume blood from the base of the retrices in seabirds, especially boobies (Sula spp.; Bowman and Billeb, 1965). Our observations are the first of this behavior on Darwin. Opuntia includes food resources obtained from this plant which are most important in the diet of $G$. scandens: seeds, fruits, insect larvae and pupae, nectar, and pollen (Grant and Grant, 1980b, 1981). The remaining vegetation categories, seeds, invertebrates, and pollen/nectar include foods produced on plants other than Opuntia.

Table 6 summarizes major differences among populations in the use of foods and feeding positions. Principal components were derived from covariances computed from untransformed diet proportions for populations of all three species combined. Only the first nine diet categories were used (Table 5). Values were rescaled to sum to 1 before computation. Population positions along the first four diet components (DC's) are shown in Figure 3.

DCl strongly represents variation among populations in the use of Opuntia (Table 6). Geospiza scandens is essentially an Opuntia specialist (Table 5; see also Grant and Grant, 1981) and it is widely separated along DC1 from all populations of $G$. fuliginosa and $G$. dif- ficilis (Fig. 3a). DC2 summarizes major differences between the latter two species. Overall, $G$. difficilis ate concealed invertebrates and seeds more often than did G. fuliginosa, which consumed more exposed seeds on the ground and vegetation (Tables 5, 6). Geospiza difficilis populations on the high islands of Pinta, San Salvador and Fernandina were most distinct from $G$. fuliginosa in this regard.

DC3 summarizes additional differences among populations of $G$. difficilis (Fig. 3b): forms on San Salvador and Pinta take invertebrates (particularly snails) more often, and concealed seeds less often, than populations on other islands (Tables 5, 6). DC4 represents variation among $G$. fuliginosa populations in the relative degree to which seeds are taken from the surface of the ground or vegetation. Subsequent components account for only minor amounts of the total variation in feeding $(\leq 3 \%)$.

Food availability differed among islands. This explains some interpopulation variation in feeding. Table 7 provides ranges of food density estimates, and demonstrates some important qualitative differences among islands. For example, ground invertebrates were relatively rare on Genovesa and Wolf, and this may explain their infrequent occurrence in $G$. difficilis diets there (Table 5). Pollen and nectar were likewise rare on 
some islands, and hence were rare or absent from $G$. fuliginosa diets there. Food availability does not simply explain all inter-island variation in diets. For example exposed seeds on rock and soil surfaces are present on all islands where $G$. difficilis occurs, yet these are heavily exploited only on the three low islands.

\section{Associations Between \\ Morphology and Diet}

Lack (1947) discussed morphological variation among populations of $G$. difficilis primarily in terms of their morphological similarities with $G$. fuliginosa and $G$. scandens. He suggested that $G$. difficilis populations similar to either $G$. fuliginosa or G. scandens in morphology would resemble them in diet. This can be examined with data in Table 4 which compares morphological $(M)$ and diet $(D)$ differences between individual $G$. difficilis populations and the mean for $G$. $f u$ liginosa and $G$. scandens.

As Lack predicted, $G$. difficilis on Genovesa is the population most similar in diet to $G$. fuliginosa (see also Fig. 3). The data also provide partial support for the idea that $G$. difficilis on Darwin and Wolf combine the feeding niches of the absent $G$. fuliginosa and $G$. scandens. Geospiza difficilis on both Darwin and Wolf are moderately similar to $G$. fuliginosa in diet, more so than any other $G$. difficilis population except Genovesa. However, while the Darwin and Wolf populations are more similar to $G$. scandens than are most other $G$. difficilis populations, the resemblance is unexpectedly low. Also, the small amount of diet overlap which exists between these $G$. difficilis forms and the Opuntia specialist, $G$. scandens, is due more to their similar use of seeds and invertebrates (DC2 and DC3) than to their similar use of Opuntia (DC1; Fig. 3).

The feeding characteristics of $G$. diffcilis on Darwin and Wolf contribute to a weak correlation between overall morphology and diet (Table 4). $M$ and $D$ are only weakly positively correlated between individual $G$. difficilis populations
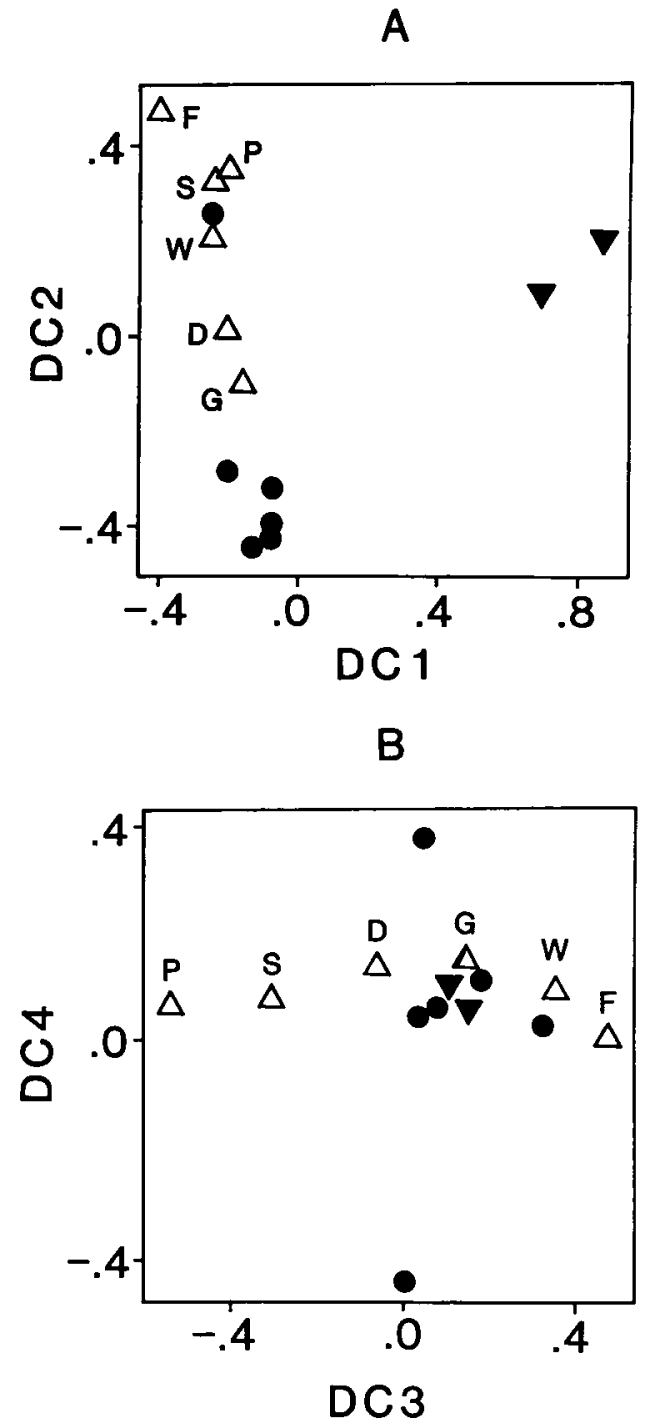

FIG. 3. Positions of $G$. difficilis, G. fuliginosa, and $G$. scandens populations along the first four principal diet components (DC). Loadings for original variables are given in Table 6. Symbols as in Figure 2.

$(N=6)$ and $G$. scandens $(r=.15) . M$ and $D$ are negatively correlated between individual $G$. difficilis populations and $G$. fuliginosa $(r=-.49)$. This unexpected trend results from the Darwin and Wolf forms of $G$. difficilis being morphologically the most distant from $G$. fuliginosa, while they are among the forms most 
TABLE 7. Food characteristics in the dry season. Figures indicate the range of variation in mean values for different sites on the study islands. No quantitative data are available for Darwin. Small seeds include all seeds commonly eaten by $G$. fuliginosa or $G$. difficilis when available. Certain abundant seeds eaten infrequently are excluded (see Schluter, 1982a).

\begin{tabular}{lccccc}
\hline & $\begin{array}{c}\text { Volume litter } \\
\left(1 / \mathrm{m}^{2}\right)\end{array}$ & $\begin{array}{c}\text { Density ground } \\
\text { inverts. } \\
\left(\mathrm{mg} / \mathrm{m}^{2}\right)\end{array}$ & $\begin{array}{c}\text { Density } \\
\text { small seeds } \\
\left(\mathrm{mg} / \mathrm{m}^{2}\right)\end{array}$ & $\begin{array}{c}\text { Density nectar- } \\
\text { producing flowers } \\
\left(\text { no./m } \mathrm{m}^{2}\right)\end{array}$ & $\begin{array}{c}\text { Percent cover } \\
\text { Opuntia }\end{array}$ \\
\hline Pinta & $2.5-9.0$ & $2.4-162$ & $23.9-302$ & $.0-1.3$ & $.0-3.4$ \\
San Salvador & $1.0-14.1$ & $10.7-470$ & $1.5-156$ & 0 & 0 \\
Fernandina & $.5-9.3$ & $1.1-55.4$ & $11.5-506$ & 0 & 0 \\
Darwin & $?$ & $?$ & $?$ & 0 & 0 \\
Wolf & .3 & 39.9 & 66.2 & 0 & 23.0 \\
Genovesa & $1.9-2.5$ & $7.2-15.5$ & $1.1-24.1$ & $.0-.7$ & $6.4-12.8$ \\
Marchena & $.6-.9$ & 13.6 & $5.0-6.2$ & $.0-2.7$ & $.0-6.4$ \\
Española & $.0-.8$ & $2.1-5.1$ & $12.5-28.4$ & 0 & $.0-6.4$ \\
Tortuga & .2 & 8.0 & 12.7 & 0 & 0 \\
\hline
\end{tabular}

similar to G. fuliginosa in diet. Also, while $G$. difficilis on Pinta and Fernandina are as close to $G$. fuliginosa in morphology as is the population on Genovesa, they are the most distant from $G$. fuliginosa in diet.

\section{DisCUSSION}

Some general features of Lack's hypothesis concerning the evolution of $G$. difficilis populations in relation to the distribution of competitors are supported by our field studies. As Lack (1947) predicted from specific morphological considerations, lowland populations of $G$. difficilis are very like $G$. fuliginosa in diet. Geospiza difficilis occurs on low islands only where $G$. fuliginosa is not present, and this is best attributed to competitive exclusion on low islands (Schluter and Grant, 1982). On high islands the diet of $G$. difficilis is quite different from the diet of the lowland form, and this is associated with food differences between the habitat types. The implication is that the diversity of habitats occupied by $G$. difficilis has been influenced by competitors, and this in turn has directly influenced the degree of morphological variation exhibited.

Attempts to understand more precisely how food conditions have influenced morphological variation in $G$. difficilis are complicated by a weak overall correlation between morphology and diet (Table
4). For example, it is not clear from the diet data why the Darwin and Wolf forms of $G$. difficilis are close to $G$. scandens in morphology. Nor is it clear why, relative to its highland populations, $G$. difficilis on Genovesa has converged to $G$. fuliginosa in some morphological traits (e.g., Body Mass, Tarsus Length) but not in others (Beak Length, Beak Length at 4 $\mathrm{mm}$; Table 2, Fig. 2). Below we discuss possible factors which may influence dietmorphology correlations, and we attempt to account for these factors in an explanation for morphological patterns in $G$. difficilis.

\section{Environmental Variation}

Morphological traits may not always reflect diet closely because of opportunistic feeding under variable food supply conditions. A correlation is expected only under food limitation, when natural selection may most strongly influence morphology (Wiens, 1977; Smith et al., 1978; Grant and Grant, 1980a; Wiens and Rotenberry, 1980, 1981; Boag and Grant, 1981).

If selection in $G$. difficilis is related to low food supplies, then the most critical period in any year is likely to be near the end of the dry season, after most foods have been depleted, but before new flowers and fruits appear. Our studies were conducted in the dry season, but possibly some visits to islands preceded the period 
of greatest resource scarcity. Darwin and Wolf were visited rather early in the dry season compared to other islands (Table 1) and seed density was still quite high on Wolf compared to other low islands (Table 7).

Possibly, $G$. difficilis on Darwin and Wolf exploit Opuntia more heavily later in the dry season (Köster and Köster, 1983), and this would explain why they have a long beak, similar to that in $G$. scandens. Or, the long beak in these two forms may be an adaptation for probing Opuntia flowers which bloom in the wet season (and possibly late in the dry season). Beck (Rothschild and Hartert, 1902) reported $G$. difficilis on Wolf feeding on flowers in the breeding season, and we observed the same behavior there in early April, 1978.

Alternatively, a long beak in $G$. diffcilis on these two islands might be an adaptation to blood feeding. Visitors to Wolf in the late dry season of different years note the high frequency of bloodfeeding by $G$. difficilis (Köster and Köster, 1983; S. Harcourt, pers. comm.). In September 1981 this behavior constituted $7 \%$ of the diet on Wolf (Table 5), but by December of the same year the proportion had increased substantially (S. Harcourt, pers. comm.). A long beak would probably facilitate probing through feathers and skin of seabrids. It may also be advantageous for a related reason: $G$. difficilis on both Darwin and Wolf is known to use its beak to pierce the eggs of seabirds which nest there in large numbers (Köster and Köster, 1983; R. I. Bowman, pers. comm.).

However, data suggest that the environmental variation hypothesis is not a sufficient explanation for the weak dietmorphology correlation recorded. First, most observations for this study were collected in the late dry season, by which time finch numbers had declined in correspondence with dwindling food supplies (Schluter, $1982 a$; Schluter and Grant, 1982, 1984). Food supply was therefore probably limiting. Second, repeat observations on dry season diets re- corded at different times in the same year and in different years give similar results to those in Table 5. Geospiza difficilis on Genovesa is one of the best-studied populations in the Galápagos, and it has been found to be invariably highly similar to G. fuliginosa in diet (Smith et al., 1978; Grant and Grant, 1980a; Schluter and Grant, 1982; pers. observ.). Geospiza difficilis on Pinta and other highland islands is generally quite different from $G$. fuliginosa in diet (Schluter, 1982a; pers. observ.). Finally, during the course of this study $G$. scandens and $G$. fuliginosa were generally observed to be feeding on those foods to which they are thought to be morphologically adapted (Table 5; Abbott et al., 1977; Smith et al., 1978; Grant and Schluter, 1984). It is therefore unlikely that this would not also be true for most $G$. difficilis populations observed at the same time.

These observations suggest that some intrinsic factors may influence diet-morphology correlations, a possibility discussed next.

\section{Morphological Interdependence}

Previous comparisons of Geospiza morphology and diet have concentrated on populations differing mainly in general beak and body size, and this variable is usually correlated with size and hardness of seeds consumed (Abbott et al., 1977; Schluter, 1982b; Schluter and Grant, 1984). However, populations of $G$. difficilis differ from one another and from related species in both size and shape (Fig. 2), and they use different foraging positions and food types. It is possible that the poor association between morphology and diet in this study is partly a consequence of evolutionary interdependence among those traits responsible for size-shape differences.

There are at least two ways in which traits may be evolutionarily interdependent. First, traits may be genetically correlated (Boag, 1983; Grant, 1983), and some traits will evolve as a correlated response to natural selection on other 
traits (Lande, 1979). Second, there may be alternative morphological solutions to the problem of exploiting particular food types. A simple consequence of such interactions is that final morphology resulting from response to a particular selection pressure may vary depending on the initial morphological and genetical characteristics of that population. Two species initially different morphologically may thus evolve to two different morphological forms in the same environment.

These considerations may help explain why populations of $G$. fuliginosa and $G$. difficilis differ in some morphological traits, even though their diets may be similar. In each species traits are correlated among populations, and lines of interpopulation allometry are largely parallel (Fig. 2). Thus the Genovesa form of $G$. difficilis has converged in general size to $G$. fuliginosa, but it retains the relatively long and pointed beak that is characteristic of the species (Fig. 2). Interestingly, in general size $G$. difficilis on Genovesa is most like the Pinta and Marchena forms of $G$. fuliginosa, which are themselves the smallest forms of this species. This is associated with a nectarfeeding habit in all three populations, in addition to the consumption of exposed seeds (Table 5). Since nectar is frequently removed from small flowers on thin branches, metabolic efficiency as well as perching ability are probably major selective factors in the evolution of small size in these three populations.

The different beaks in these three populations are used in a different manner, but to the same end. One of the most important sources of nectar on Pinta, Marchena and Genovesa is the small flower of Waltheria ovata. While the sharp-beaked $G$. difficilis on Genovesa probes the flowers with the entire beak to obtain nectar, the more blunt-beaked $G$. fuliginosa on the other two islands uses only the lower mandible (pers. observ.). We do not know whether the two species remove nectar with equal efficiency, although they appear to do so; each probe at a maximal rate of $30-40$ flowers/min (pers. observ.).

\section{Other Factors}

While diet per se is probably the major determinant of morphological variation in $G$. difficilis, other environmental factors may also be important. A possible example involves Wing Length, which varies among populations partly independently of general size (Table 3 ). Relative Wing Length is greatest in the lowland populations of $G$. difficilis (Fig. 2). This is associated with an arid-zone distribution (Fig. 1), and may allow for more efficient heat-loss in such habitats (Hamilton, 1961; James, 1970). Flight energetics could also influence variation in relative Wing Length (e.g., Feinsinger et al., 1979). Lowland forms of $G$. difficilis seem to fly more frequently, and they are less restricted in their movements in space than are highland forms (Schluter, 1984). This may be a consequence of differences among habitats in the dispersion and renewal patterns of resources exploited.

\section{SUMMARY}

The morphology of $G$. difficilis varies on different islands in the Galápagos (Fig. 2). Lack (1947) argued that beak and body size in this species are related to feeding, and noted that variation in morphology is associated with inter-island differences in the presence or absence of potential competitor species. We investigated the relationship between inter-island morphological variation in $G$. difficilis and in two potential competitor species, $G$. $f u$ liginosa and $G$. scandens, and their dry season diets.

Our observations support some of Lack's general conclusions concerning the significance of morphological variation in $G$. difficilis. For example, populations of $G$. difficilis are similar in diet to $G$. fuliginosa on islands where this species is absent. However, overall morphological distances between populations of $G$. difficilis and the other two species did not successfully predict diet differences. There are at least two reasons for discrepancies. 
First, environments vary seasonally and annually, and populations may not all have been studied during the most critical periods of food limitation. Second, traits have not evolved independently in $G$. difficilis, and this complicates dietmorphology comparisons, for example when there are alternative morphological solutions to a single foraging problem. Consideration of these factors helps clarify the significance of variation among $G$. difficilis populations in certain morphological traits. Beak length and body size appear to be particularly important in relation to food. On the low island of Genovesa, $G$. difficilis has become smaller, and this is correlated with a diet of small seeds and flower nectar. On the low islands of Darwin and Wolf $G$. difficilis has a relatively longer beak than other populations have. This may be an adaptation to cactus-feeding, but some data indicate that it may have evolved to facilitate blood- and egg-feeding.

\section{ACKNOWLEDGMENTS}

We thank Trevor Price, Ronald Pulliam, Robert Ricklefs and Robert Voss for comments and discussion. David Anderson, Ronald Brooks, Erick Greene, Sylvia Harcourt, Stephen Millington, Douglas Nakashima, Trevor Price, Laurene Ratcliffe and Diego Villalba provided field assistance. Robert Bowman provided some useful unpublished notes on Isla Darwin and the finches there. Stephen Millington and Peter Boag provided unpublished measurements and diet data on Daphne $G$. scandens. We thank the Estación Científica Charles Darwin for logistic support. Funding came from NSF grants DEB 77-2337 and DEB 7921119 to P.R.G., and a Frank M. Chapman grant, and Rackham School of Graduate Studies Block and Dissertation grants, to D.S. The work was done with the permission of the Dirección General de Desarollo Forestal, Quito.

Literature Cited

Aвbott, I., L. K. AbBott, And P. R. Grant. 1977. Comparative ecology of Galápagos ground finches (Geospiza Gould): evaluation of the importance of floristic diversity and interspecific competition. Ecol. Monogr. 47:151-184.

BoAG, P. T. 1983. The heritability of external morphology in the Darwin's finches (Geospizinae) of Daphne Major Island, Galápagos. Evolution 37:877-894.

BoAG, P. T., AND P. R. Grant. 1981. Intense natural selection in a population of Darwin's finches (Geospizinae) in the Galápagos. Science 214:82-85.

Bowman, R. I., AND S. I. Billeb. 1968. Bloodeating in a Galápagos finch. Living Bird 4:29 44.

FALCONER, D. S. 1981. Introduction to Quantitative Genetics, 2nd ed. Longman, London.

Feinsinger, P., R. K. Colwell, J. Terborgh, AND S. B. Chaplin. 1979. Elevation and the morphology, flight energetics, and foraging ecology of tropical hummingbirds. Amer. Natur. 113: 481-497.

Gatz, A. J. 1979. Community organization in fishes as indicated by morphological features. Ecology 60:711-718.

Grant, B. R., and P. R. Grant. 1981. Exploitation of Opuntia by birds on the Galápagos. Oecologia 49:179-187.

Grant, P. R. 1981. Speciation and the adaptive radiation of Darwin's finches. Amer. Sci. 69: 653-663.

-1983. Inheritance of size and shape in a population of Darwin's finches, Geospiza conirostris. Proc. Roy. Soc. London. B 220:219-236.

Grant, P. R., AND P. T. BoAG. 1980. Rainfall on the Galápagos and the demography of Darwin's finches. Auk 97:227-244.

Grant, P. R., ANd B. R. Grant. 1980a. The breeding and feeding characteristics of Darwin's finches on Isla Genovesa, Galápagos. Ecol. Monogr. 50:381-410.

- $1980 \mathrm{~b}$. Annual variation in finch numbers, foraging and food supply on Isla Daphne Major, Galápagos. Oecologia 46:55-62.

Grant, P. R., AND D. SCHLuter. 1984. Interspecific competition inferred from patterns of guild structure. In D. R. Strong, D. S. Simberloff, L. G. Abele, and A. B. Thistle (eds.), Ecological Communities: Conceptual Issues and the Evidence. Princeton Univ. Press, Princeton.

HAMANN, O. 1979. Regeneration of vegetation on Santa Fe and Pinta islands, Galápagos, after the eradication of goats. Biol. Conserv. 15:215-236.

- 1981. Plant communities of the Galápagos islands. Dansk Botanisk Arkiv 34:1-163.

HAMILTON, T. H. 1961. The adaptive significance of intraspecific trends of variation in wing length and body size among bird species. Evolution 15 : 180-195.

HARRIS, M. P. 1973. The Galápagos avifauna. Condor 75:265-278.

Hurlbert, S. H. 1978. The measurement of niche overlap and some relatives. Ecology 59:67-77.

JAMES, F. C. 1970. Geographic size variation in 
birds and its relationship to climate. Ecology 51: 365-390.

- 1982. The ecological morphology of birds: a review. Ann. Zool. Fennici 19:265-275.

KEAST, A. 1972. Ecological opportunities and dominant families, as illustrated by the neotropical Tyrannidae (Aves). Evol. Biol. 5:229277.

KÖSTER, F., AND H. KöSTER. 1983. Twelve days among the "vampire finches" of Wolf island. Noticias de Galápagos 38:4-10.

LACK, D. 1947. Darwin's Finches. Cambridge Univ. Press, Cambridge.

LANDE, R. 1979. Quantitative genetic analysis of multivariate evolution, applied to brain : body size allometry. Evolution 33:402-416.

Pimentel, R. A. 1979. Morphometrics, the Multivariate Analysis of Biological Data. Kendall/ Hunt, Dubuque, Iowa.

PrICE, T. D. 1984. The evolution of sexual size dimorphism in Darwin's finches. Amer. Natur. 123:500-518.

Ricklefs, R. E., D. Cochran, AND E. R. Pianka. 1981. A morphological analysis of the structure of communities of lizards in desert habitats. Ecology 62:1474-1483.

Ricklefs, R. E., AND J. Travis. 1980. A morphological approach to the study of avian community organization. Auk 97:321-338.

ROTHSCHILD, W., AND E. HARTERT. 1902. Further notes on the fauna of the Galápagos Islands. Notes on the birds. Novit. Zool. 9:381-418.

SCHLUTER, D. 1982a. Distributions of Galápagos ground finches along an altitudinal gradient: the importance of food supply. Ecology 63:15041517. 1982b. Seed and patch selection by Galápagos ground finches: relation to foraging efficiency and food supply. Ecology 63:1106-1120. 1984. Feeding correlates of breeding and social organization in two Galápagos finches. Auk 101:59-68.

Schluter, D., And P. R. Grant. 1982. The distribution of Geospiza difficilis in relation to $G$. fuliginosa in the Galápagos islands: tests of three hypotheses. Evolution 36:1213-1226.

1984. Determinants of morphological patterns in communities of Darwin's finches. Amer. Natur. 123:175-196.

SimberlofF, D., AND W. BoECKlen. 1981. Santa Rosalia reconsidered: size ratios and competition. Evolution 35:1206-1228.

Smith, J. N. M., P. R. Grant, B. R. Grant, I. J. AbBott, AND L. K. Aвbott. 1978. Seasonal variation in the feeding habits of Darwin's ground finches. Ecology 59:1137-1150.

WIENS, J. A. 1977. On competition and variable environments. Amer. Sci. 65:590-597.

Wiens, J. A., AND J. T. Rotenberry. 1980. Patterns of morphology and ecology in grassland and shrubsteppe bird populations. Ecol. Monogr. 50:287-308.

. 1981. Morphological size ratios and competition in ecological communities. Amer. Natur. 117:592-599.

Wiggins, I. L., AND D. M. Porter. 1971. Flora of the Galápagos Islands. Stanford Univ. Press, Stanford.

Corresponding Editor: R. E. Ricklefs 